\title{
Bacterial Magnetosome: A Novel Biogenetic Magnetic Targeted Drug Carrier with Potential Multifunctions
}

\author{
Jianbo Sun, ${ }^{1}$ Ying Li, ${ }^{2}$ Xing-Jie Liang, ${ }^{3,4}$ and Paul C. Wang ${ }^{5}$ \\ ${ }^{1}$ Department of Microbiology and Immunology, College of Physicians and Surgeons, Columbia University, New York, NY 10032, USA \\ ${ }^{2}$ State Key Laboratories for Agro-biotechnology and College of Biological Sciences, China Agricultural University, Beijing 100193, China \\ ${ }^{3}$ Laboratory of Nanomedicine and Nanosafety, Division of Nanomedicine and Nanobiology, National Center for Nanoscience and \\ Technology, Beijing 100190, China \\ ${ }^{4}$ CAS Key Laboratory for Biomedical Effects of Nanomaterials and Nanosafety, Chinese Academy of Sciences, Beijing 100190, China \\ ${ }^{5}$ Laboratory of Molecular Imaging, Department of Radiology, Howard University, Washington, DC 20060, USA
}

Correspondence should be addressed to Xing-Jie Liang, liangxj@nanoctr.cn and Paul C. Wang, pwang@howard.edu

Received 30 May 2011; Accepted 12 July 2011

Academic Editor: Donglu Shi

Copyright ( 2011 Jianbo Sun et al. This is an open access article distributed under the Creative Commons Attribution License, which permits unrestricted use, distribution, and reproduction in any medium, provided the original work is properly cited.

\begin{abstract}
Bacterial magnetosomes (BMs) synthesized by magnetotactic bacteria have recently drawn great interest due to their unique features. BMs are used experimentally as carriers for antibodies, enzymes, ligands, nucleic acids, and chemotherapeutic drugs. In addition to the common attractive properties of magnetic carriers, BMs also show superiority as targeting nanoscale drug carriers, which is hardly matched by artificial magnetic particles. We are presenting the potential applications of BMs as drug carriers by introducing the drug-loading methods and strategies and the recent research progress of BMs which has contributed to the application of BMs as drug carriers.
\end{abstract}

\section{Introduction}

Nanoscale drug carriers for targeted drug delivery have great potential [1-4] to resolve the issues associated with regular drug administration such as nonspecific biodistribution of pharmaceuticals; the lack of drug specific affinity and the necessity of a large dosage to achieve high local concentration; the crossing of biological barriers such as organs, cells, and intracellular biolayers; and nonspecific toxicity and other adverse side effects (immunity, neural systems, etc.) due to high drug doses $[5,6]$.

Pharmaceutical carriers include soluble polymers, microstructures, cell ghosts, lipoproteins, liposomes, dendrimers, micelles and so on [2-6], which can all be designed for drug delivery vehicles. Such vehicles include (a) direct application of carriers with drug into the affected zone; (b) passive drug accumulation in the tissues with leaky vasculature; (c) physiological targeting based on abnormal $\mathrm{pH}$ and/or temperature in the pathological zone; (d) magnetic targeting under the use of an external magnetic field; (e) intelligentized targeting using specific molecules such as ligands or antibodies, which can recognize the targeted area and increase the affinity to it.

Magnetic-targeted drug carriers are prepared using $\mathrm{Fe}_{3} \mathrm{O}_{4}$ or $\mathrm{Fe}_{2} \mathrm{O}_{3}$ as a core and coated with biocompatible polymers for drug delivery [7-9] due to their attractive advantages for medical applications which are (a) paramagnetism for magnetic resonance imaging (MRI); (b) position altering with magnetic field; (c) hyperthermia with an external alternating magnetic field; (d) controllable size; (e) surface modification with diverse bioactive molecules; (f) nonsignificant safety concerns. This technology has evolved rapidly since the 1970s [10], although its application has been hampered by problems such as low drug loading, propensity of congregating, poor dispersion, and difficult control of microspheric shape or size [9]. Bacterial magnetosomes (BMs) [11] synthesized by magnetotactic bacteria have recently drawn great interest [12-15] as alternatives for targeting drug carriers due to their unique features such as paramagnetism, nanoscale, narrow-size distribution, and being bounded to the membrane [16-20]. 


\section{Characterization of BMs}

Magnetosomes are found in all magnetotactic bacteria and consisted of magnetic iron mineral particles and present species-specific characteristics. Magnetosomes from the same species have the same unique composition and uniform morphology with narrow-size distribution. In various magnetotactic bacteria, magnetosomes have shapes in cubo-octahedral, elongated hexagonal prismatic, and bulletshaped morphologies (Figure 1) [16, 21-23]. Magnetosomes in most magnetotactic bacteria strains consist of magnetite, $\mathrm{Fe}_{3} \mathrm{O}_{4}$. The Raman Spectrum of BMs from $M$. gryphiswaldense shows resemblance to $\mathrm{Fe}_{3} \mathrm{O}_{4}$. The FTIR spectrum of BMs also shows the presence of $\mathrm{Fe}_{3} \mathrm{O}_{4}$ [24]. Typical particle sizes are $35-120 \mathrm{~nm}$, however, in some locations, crystals larger than $200 \mathrm{~nm}$ are found. Magnetosomes, in several magnetotactic bacteria from sulfuric environments, consist of the iron-sulfide mineral greigite, $\mathrm{Fe}_{3} \mathrm{~S}_{4}$, which is ferrimagnetically ordered $[16,25]$.

2.1. Characterization of Magnetosome Membrane. All magnetosomes examined to date have a lipid bilayer admixed with special proteins, which is termed magnetosome membrane. The magnetosome membrane of $M$. magnetotacticum MS1 contains neutral lipids and free fatty acids; as well as glycolipids, sulfolipids, and phospholipids (in a weight ratio of $1: 4: 6)$. The phospholipids include phosphatidylserine and phosphatidylethanolamino. There are numerous proteins detected in the magnetosome membrane which were not found in other cell membranes or soluble fractions [18]. The fatty acid and proteomic analysis of the magnetosome membrane of $M$. magneticum AMB-1 showed a striking similarity between the cytoplasmic and magnetosome membrane profiles $[19,26]$. The results showed that palmitoleic acid and oleic acid account for $90 \%$ of the total fatty acids and phospholipids compose $58 \%$ of the total lipid; with phosphatidyl ethanolamino accounting for $50 \%$ of the total phospholipids. 78 identified magnetosome membrane proteins were also found to be common in the cytoplasmic membrane, several of which are related to magnetosome biosynthesis.

The magnetosome membrane of $M$. gryphiswaldense is composed of phospholipids and fatty acids, which is similar to that from outer and cytoplasmic membranes but with different proportions [20]. There are at least 18 proteins that make up the magnetosome subproteome, and most of these proteins are unique for M. gryphiswaldense. The FTIR spectrum of BMs has shown these membrane lipids and the amino groups [24].

Analysis of magnetosome membrane proteins in different Desulfovibrio magneticus strains RS-1, AMB-1, and MSR1 indicated three magnetosome-specific proteins MamA (Mms24), MamK, and MamM. The collagen-like protein and alleged iron-binding proteins are considered to play key roles in magnetite crystal formation and are identified as specific proteins in strain RS-1. The newly identified magnetosome membrane proteins might contribute to the formation of the unique irregular, bullet-shaped crystals in the strain [27].
The presence of polarizable primary amino groups in the magnetosome membrane offers an explanation of the elevation of external $\mathrm{pH}$ increasing the surface negativity of magnetosome membrane. The zeta potential of BMs from $M$. gryphiswaldense in pH 7.4 buffer is $-24.4 \pm 4.0 \mathrm{mV}$. The zeta potential for the BMs of M. magneticum AMB-1 changes from -2.5 to $-25.0 \mathrm{mV}$ when the $\mathrm{pH}$ value changes from 4.0 to $7.0[24,28]$. The biodistribution of nanosize drug carriers following intravenous administration depends heavily on particle size and surface properties such as surface charge and hydrophobicity [29, 30]. The mononuclear phagocytic system (MPS), or reticuloendothelial system (RES), mainly consists of macrophages in the liver and spleen. The RES has the ability to remove unprotected nanoparticles from the bloodstream within seconds after intravenous administration. In general nanoscale size of BMs (35-120 nm) and the negative zeta potential of BMs are good to reduce liver clearance. It has been shown that after the injection of BMs through sublingual vena; BMs were accumulated in the liver of SD rats [24].

2.2. Magnetic Properties of BMs. The analysis of the magnetic properties of magnetosomes focused on the magnetic microstructure, hysteresis, and relaxation time. Researches by various groups showed that magnetosomes from M. Magnetotacticum MS-1, M. magneticum AMB-1, M. gryphiswaldense, the marine vibrioid strain $\mathrm{MV}-1$, and the coccoid strain MC-1 were all single-magnetic-domain particles $[11,16,21,31-36]$. The magnetization directions of small super paramagnetic crystals were constrained by magnetic interactions with larger crystals in the magnetosome chain having predominant saturation magnetization [32]. Shape anisotropy was found to dominate magnetocrystalline anisotropy in elongated crystals, grain elongation, and separation for chains of identical magnetite grains. The inclusion of magnetic interactions was found to decrease the blocking volume, thereby increasing the range of stable single magnetic domain, a scale not attainable for chemically synthesized nanoparticles [37].

Holograms showed a coercive field of 300 Oe for $M$. magnetotacticum [38] and coercive field of 300-450 Oe for the MV-1 chain [32]. The exact value of coercive fieldfor any given magnetosome chain is sensitive to the particle size, separation, and chain length, as well as magnetocrystalline anisotropy [31]. For aqueous suspensions of magnetosomes extracted from M. gryphiswaldense, the coercivity at room temperature is $0.7 \mathrm{kA} / \mathrm{m}$, while coercivity increases to $2.6 \mathrm{kA} / \mathrm{m}$ or $6.5 \mathrm{kA} / \mathrm{m}$ Bby suspending magnetosomes in aqueous solution of gelatin, with subsequent particle immobilization by gelation, coercivity increases to $2.6 \mathrm{kA} / \mathrm{m}$ or $6.5 \mathrm{kA} / \mathrm{m}[39,40]$. Compared to $20 \mathrm{~A} / \mathrm{m}$ of the commercially available ferrofluid Resovist, this extremely high value confirms the high anisotropy-related Néel relaxation time. The magnetic losses, converted into heat in hyperthermia, were determined calorimetrically to be $960 \mathrm{~W} / \mathrm{g}$ at $10 \mathrm{kA} / \mathrm{m}$ and $410 \mathrm{kHz}$. This value is exceptionally large and may even exceed those of compared metallic magnetic particles such as cobalt particles, which are hardly matched by artificial magnetic particles $[39,41]$. 


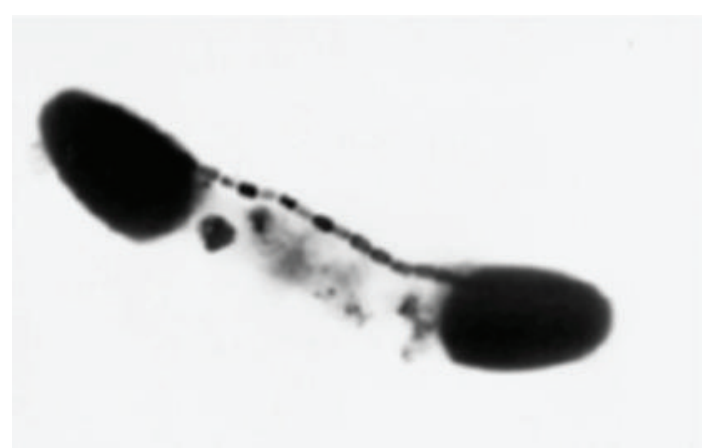

(a)

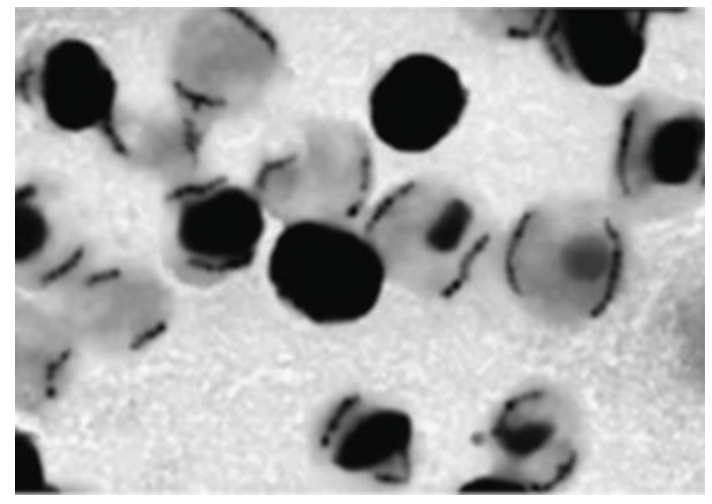

(c)

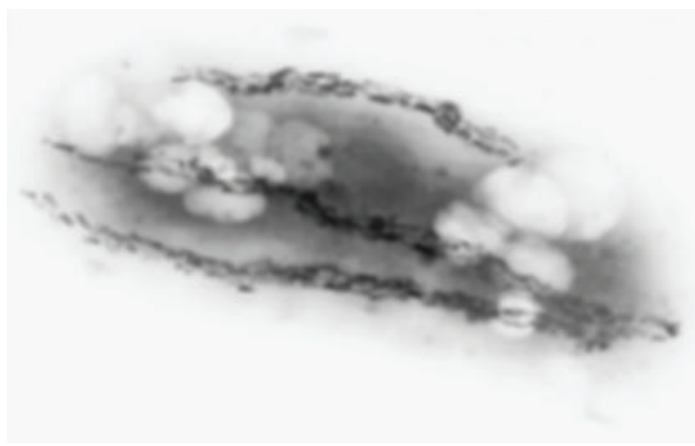

(b)

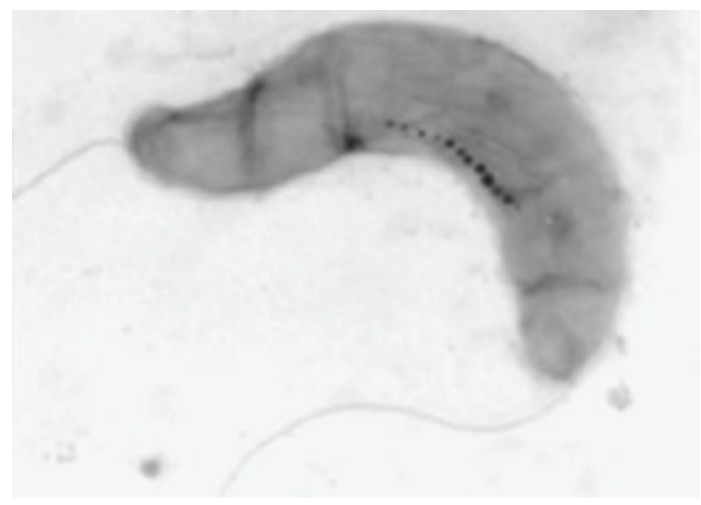

(d)

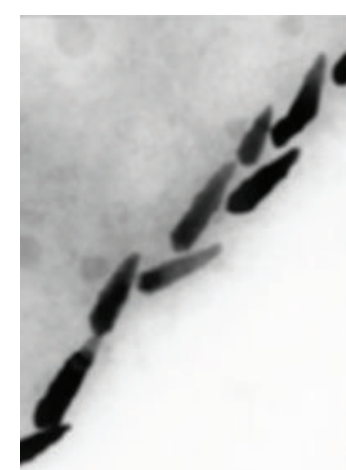

(e)

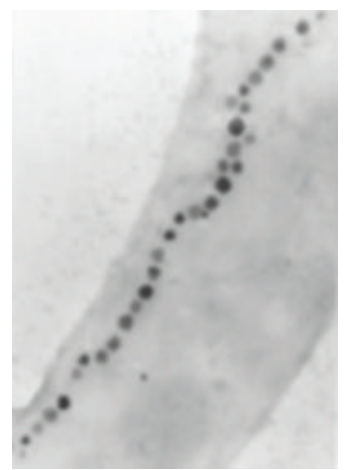

(f)

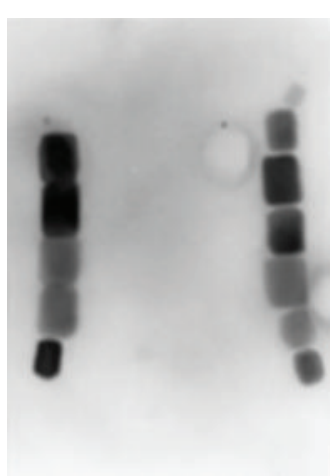

(g)

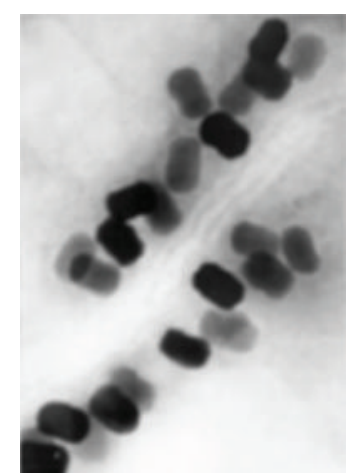

(h)

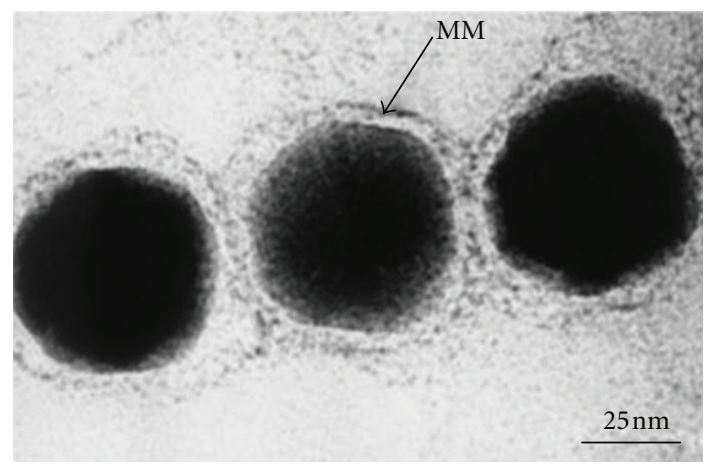

(i)

FIGURE 1: Magnetotactic bacteria with magnetosomes (a-d) and its membrane (i). Various morphologies of magnetosomes (e-h) [22, 23]. 
Alphandéry et al. [42] examined mechanisms of heat production by whole intact cells and extracted chains and individual magnetosomes of the magnetotactic bacterium $M$. magneticum strain AMB-1- when exposed to an oscillating magnetic field of frequency $108 \mathrm{kHz}$ and field amplitudes of 23 and $88 \mathrm{mT}$. In this study, magnetosomes did not contain magnetite as the magnetite oxidized to maghemite. Intact bacterial cells that contain chains of magnetosomes, heat is generated through hysteresis losses yielding specific absorption rates of $115 \pm 12 \mathrm{~W} / \mathrm{gFe}$ at $23 \mathrm{mT}$ and $864 \pm$ $9 \mathrm{~W} / \mathrm{gFe}$ at $88 \mathrm{mT}$. When the chains of magnetosomes are extracted from the bacterial cells and exposed to the same magnetic field, there is an additional contribution to the heat-producing mechanism due to the rotation of the magnetosomes. This contribution results in higher observed specific absorption rates of $864 \pm 13 \mathrm{~W} / \mathrm{gFe}$ at $23 \mathrm{mT}$ and $1242 \pm 24 \mathrm{~W} / \mathrm{gFe}$ at $88 \mathrm{mT}$. Individual magnetosomes whose membranes had been removed produced specific absorption rate values of $529 \pm 14 \mathrm{~W} / \mathrm{gFe}$ at $23 \mathrm{mT}$ and $950 \pm 18 \mathrm{~W} / \mathrm{gFe}$ at $88 \mathrm{mT}$.

Magnetotactic bacteria embedded with magnetosomes affect the T2-relaxation more greatly than T1-relaxation rate in MRI system [35] and can be used as a negative contrast agent for MRI. The physicochemical and magnetorelaxometric characterizations of bacterial magnetosomes and iron oxide nanoparticles were investigated. The longitudinal and transverse relaxivities of the magnetosomes were studied with a $1.5 \mathrm{~T}$ MRI system to be R $1=7.688 \mathrm{mmol}-1 \mathrm{~s}-1$ and $\mathrm{R} 2=147.67 \mathrm{mmol}-1 \mathrm{~s}-1$, respectively [39]. Magnetosomes in agarose gel were analyzed [43] using a 3.0 T MRI-scanner and showed T2 relaxivity of $1175 \mathrm{mM}-1 \mathrm{~s}-1$, which was larger than synthetic magnetic nanoparticles with $551 \mathrm{mM}-1 \mathrm{~s}-1$ and Resovists with $230 \mathrm{mM}-1 \mathrm{~s}-1$. Both bacterial magnetosomes and synthetic magnetites can be used as a negative contrast agents and show slight $\mathrm{T} 1$ effects and strong $\mathrm{T} 2$ effects on MRI images. The signal attenuation of bacterial magnetite samples is more prominent than that of synthetic magnetite samples at the same concentration because bacterial magnetosomes have larger mean aggregate size, better dispersion, and stronger ferromagnetism compared to synthetic magnetites.

2.3. Biocompatibility of BMs. BMs have been predicted to be highly biocompatible because they are formed by bacterial cells rather than artificially synthesized. BMs also pose potential risks as they are nanosized particles isolated from bacterial cells and their membrane contains various nonhuman proteins $[18-20,26]$. Chemical toxicity of BMs from iron ions is negligible $[44,45]$ due to the insolubility of $\mathrm{Fe}_{3} \mathrm{O}_{4}$. Therefore, the toxicity of BMs may be primarily due to (a) their nanoscale size, which leads to embolism, blockage, and deposition in the body and (b) impurities, particularly proteins, nucleic acids, and polysaccharides associated with BMs extracted from bacterial cells, resulting in immunotoxicity.

Sun et al. have studied the biocompatibility of BMs and have shown the body tissue distribution and host tissue elimination following administration of BMs into the vascular system [24] and in vitro cytotoxicity for mouse fibroblasts [46]. BMs displayed targeted distribution in SD rat liver, suggesting that BMs may be less likely to congregate than other nanoparticles; that is, BMs may avoid incurring organ congestion or infarction in vivo since they can be transferred from the sublingual vein to the liver. Purified and sterilized magnetosomes were found to be nontoxic to mouse fibroblasts in vitro. The injection of $1 \mathrm{mg}$ BMs did not increase body temperature of rabbits during the pyrogen test, which showed antigens or pyrogens free with BMs administration [47].

The biocompatibility of purified magnetosomes was also evaluated comprehensively by Sun et al. It was found that magnetosomes showed slight acute toxicity, immune toxicity, and cytotoxicity [47]. The LD50 of BMs was $62.7 \mathrm{mg} / \mathrm{kg}$ when injected into the sublingual vein of SD rats. Further studies, with injection of $40 \mathrm{mg} / \mathrm{kg}$ BMs, showed no significant difference between BM-treated and nontreated control rats in terms of routine blood exam results, liver and kidney function tests, organ coefficients of major organs, or Stimulation Index of lymph cells with ConA and/or LPS antigens. The histological examination of major organs from these $40 \mathrm{mg} / \mathrm{kg}$ BM-treated rats showed no obvious pathological changes, except increased number of vacuoles in livers and thicker interlobular septa in lungs. BMs showed little cytotoxic effect on H22, HL60, or EMT6 cells. Incubation with $9 \mu \mathrm{g} / \mathrm{mL}$ BMs neither inhibited nor stimulated the growth of all three cells and had no effect on DNA content, cell size, or cell membrane integrity. Kim et al. reported that magnetosomes without surface modification were incorporated into endothelial progenitor cells in vitro, and cells containing BMs showed high viability [48].

\section{Superiority of BMs as Targeted Nanoscale Drug Carriers}

Bacterial magnetosomes also show superiority as targeting nanoscale drug carriers, which is hardly matched by artificial magnetic particles. Using magnetosomes of $\mathrm{M}$. gryphiswaldense as an example, BMs show superiority as follows: (a) very narrow size distribution $(25-55 \mathrm{~nm})$ and uniform morphology, which is biogenetically controllable and reproducible; (b) an inorganic component of $\mathrm{Fe}_{3} \mathrm{O}_{4}$ with high purity [49]; (c) stable single-magnetic-domain particles, which show paramagnetism with extremely high coercivity values, exceptionally larger magnetic losses converted into heat in hyperthermia, and more obvious T2 signal attenuation in MRI than that of synthetic magnetite samples; (d) negatively charged surface and better dispersion due to polarized primary amino groups in the magnetosome bilayer lipid membrane; (e) easy functionalization with diverse bioactive molecules because of the abundance of primary amino groups in the surface of magnetosomes; (f) potentially slow drug release from magnetosomes in vivo due to the digestible magnetosome membrane; (g) a wellestablished large-scale production method of magnetosomes with high purity [50, 51]; (h) high biocompatibility. 


\section{Drug-Loading Strategies with BMs}

BMs are able to be modified very easily with diverse bioactive molecules due to the abundance of primary amino groups on the surface of magnetosome membrane and chimeric proteins displayed specifically on the surfaces of genetically engineered isolated magnetosomes [52]. There are two major drug-loading strategies: directly loading drugs to BMs with dual function linkers, and indirectly loading drugs to BMs with linkers after modification of BMs and/or drugs.

4.1. Direct Drug-Loading onto BMs with Dual Functional Linkers. There are many chemotherapeutic drugs which contain one or more amino groups per drug molecule. Doxorubicin, epirubicin, daunorubicin, idarubicin, and pirarubicin contain one amino group per molecule, while mitomycin, bleomycin, and peplomycin contain multiamino groups per molecule. BMs can be linked to these drugs by the homobifunctional crosslinking agents such as aliphatic binary aldehyde, diisocyanates, diisothiocyanates, di(succinimido) aliphatic esters, and their derivatives (Table 1) [53]. Drugs with carboxyls or phosphate groups also can be linked to the amino groups of BMs by using 1-Ethyl-3-[3-dimethyllam-inopropyl] carbodiimide (EDC).

4.2. Indirect Drug-Loading onto BMs After Modification of $B M s$ and/or Drugs. Drugs without amino or carboxyl groups cannot be directly linked to BMs through the previously mentioned methods. There are three ways to load such drugs to BMs: attaching an amino or carboxyl group to the drugs by modification of the drugs, modifying the BMs without changing the drug molecules, and modifying both the drug molecules and BMs so that they can be linked with bifunctional reagents.

Drugs with sulphydryl or disulfide bond can be linked to BMs with modified SPDP (N-Succinimidyl 3-[2-pyridyldithio] propionate) and then reduced with DTT (Dithiothreitol). For example, antibodies can be linked to BMs by this method $[54,55]$. It is simple to switch amino groups into sulfydryls in the BMs or drugs when Traults reagent 2iminothiolane reacts with primary amino groups [53]. This reaction provides more choices for drug loading onto BMs. Drugs with primary amino groups can also be loaded onto BMs with this indirect method. For other drugs without amino group, sulphydryl or disulfide bond, drug loading onto BMs can be achieved by introducing one of these residues in the drugs and then using the strategies mentioned above.

Another unique method to load drugs onto BMs is by linking BMs with macromolecules, which are loaded with numerous small drug molecules [56]. Such macromolecules include poly-Glu, poly-Lys, poly-Asp, polyethylene glycol, and dextran. Poly-L-glutamic acid (PLGA) is a polymer of amino acids which contains multicarboxyl groups and only one single amino group. The single amino group of PLGA can be masked with a thiol group first and form PLGA-3-[2pyridyldithio] propionyl (PLGA-PDP). PLGA-PDP, with the help of EDC, can react with small drug molecules carrying amino groups such as doxorubicin (DOX) and form PDPPLGA-(DOX) $n$. This compound then reacts with the BMs modified with SPDP and DTT, and the PLGA-(DOX) $n$ can be loaded onto BMs. The process is summarized in Figure 2.

There are also drug loading methods without additional chemical reactions. For example, BMs have a negatively charged surface can be modified with cationic silane such as $\mathrm{N}$ (trimethoxysilylpropyl) isothiouronium chloride, 3Aminopropyltriethoxysilane, and 3-[2-(2-aminoethyl)-ethylamino]-propyltrimethoxysilane. The modified BMs show a cationic surface and can absorb nucleic acid drug [57, 58]. Protein A can be expressed in the membrane of BMs with genetic engineering can conjugate antibody drugs directly $[52,59]$.

\section{Drug-Loading Types with BMs}

There are four major groups of drugs that are able to be loaded onto BMs: protein drugs, nuclei acid drugs, radioactive isotopes, and chemotherapeutic drugs.

5.1. Protein Drugs. Protein drugs come in all shapes and sizes: recombinant human proteins such as insulin, growth hormone, and erythropoietin; monoclonal antibodies such as Remicade, Rituxan, and Erbitux; viral or bacterial proteins used as vaccines to elicit a specific immune response [60]. These protein drugs on the market fail to deliver in one or more target areas because they are digested or disrupted very readily during the process of crossing biological barriers such as organs, cells, and intracellular compartments. Therapeutic anticancer antibodies suffer from poor curative effects against solid tumors. Solid tumors are usually bounded with a pyknotic basement membrane and show lymphatic backflow obstacles, which impede the transfer of antibodies into solid tumors. This drawback can be overcome if the antibodies are loaded onto BMs and maintained in the solid tumors with magnets.

Methods for loading proteins onto BMs were developed by the research group led by T. Matsunaga. In 1987, Matsunaga et al. successfully immobilized glucose oxidase and uricase on BMs. The activity of glucose oxidase immobilized on BMs was 40 times than that of immobilized artificial magnetites or Zn-ferrite particles. Both glucose oxidase and uricase coupled with BMs retained their activities when they were reused five times [61]. The same research group also immobilized FITC conjugated anti-IgG antibodies on BMs, which were modified with glutaraldehyde or SPDP for the detection of allergen [19, 54, 55]. In 2001, the group loaded Hemoglobin A1c (HbA1c) onto modified BMs, which were coupled with m-aminophenylboronic acid (mAPB) by using homobifunctional crosslinker, Bis(succcimidyl)suberate (BS3) (Figure 3) [62].

Recombinant BMs with Protein A expressed on their surface were constructed using magA. MagA is a key gene in the BMs biosynthesis of magnetotactic bacteria. Homogenous chemiluminescence enzyme immunoassay using antibody bound Protein A-BMs complexes was developed for detection of human IgG (Figure 4) [52, 59]. 
TABLE 1: Homobifunctional cross linkers that can react with amino group [53].

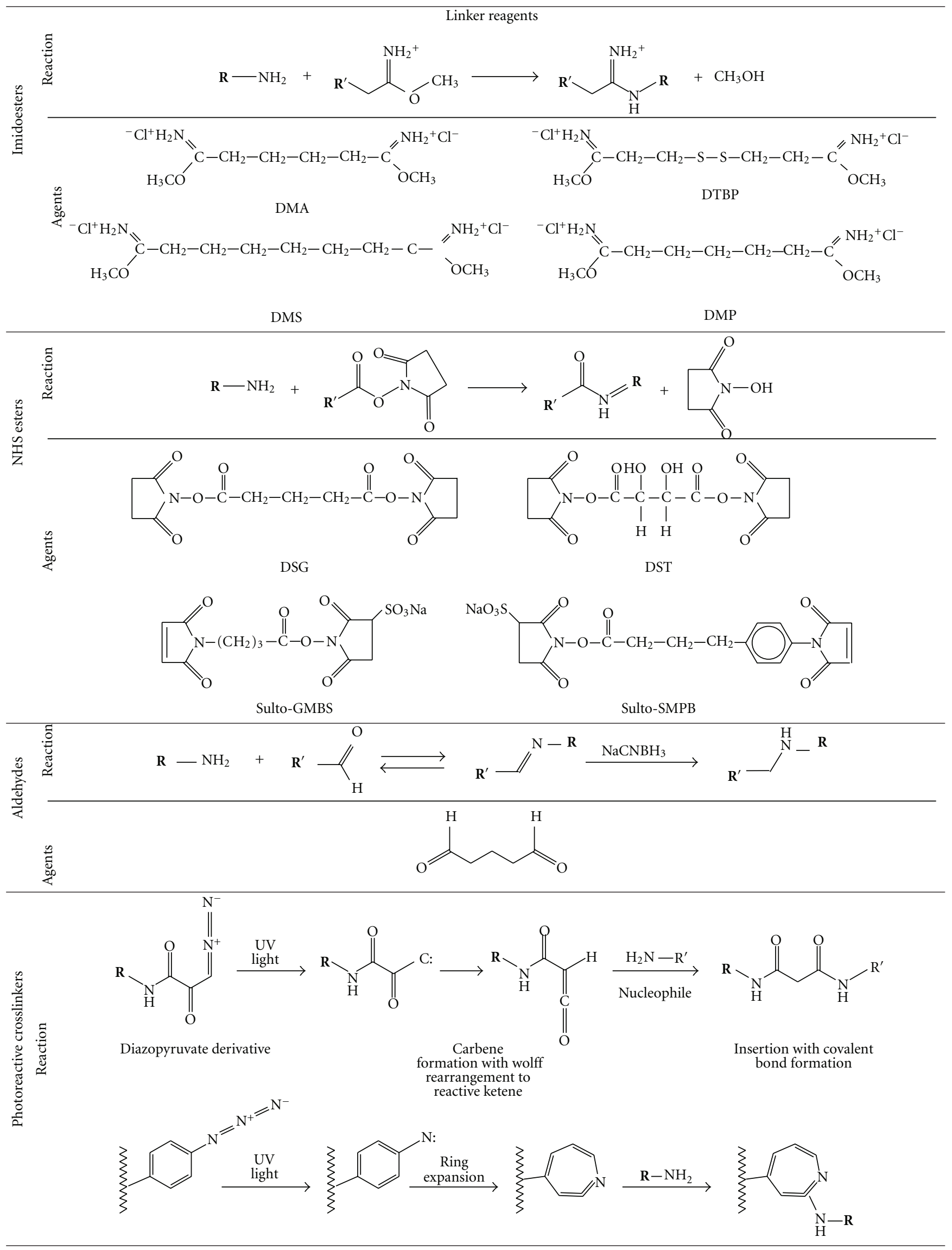


Journal of Nanomaterials

7

TABle 1: Continued.

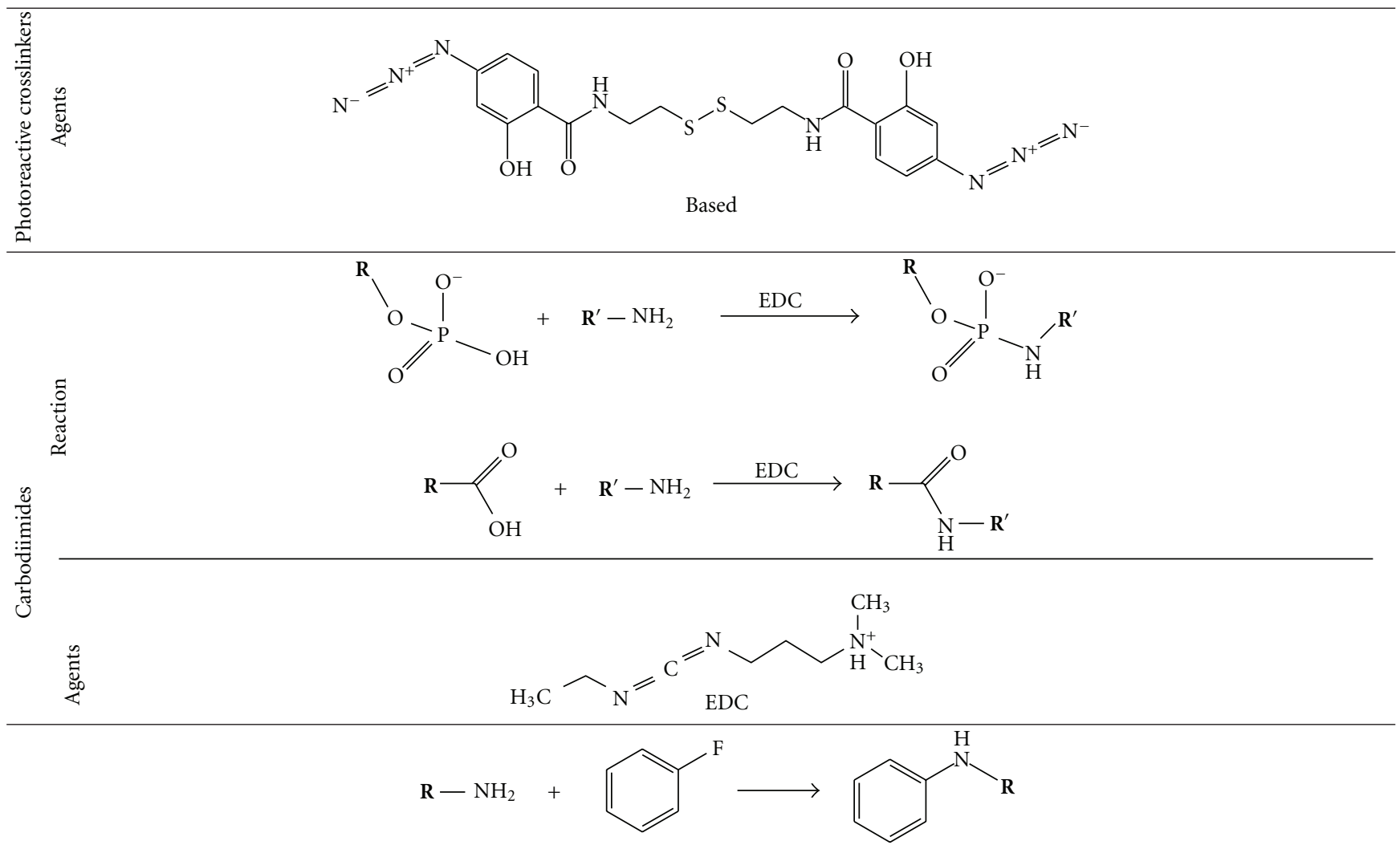

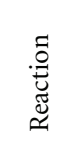<smiles>[R]NC([R])=O</smiles>

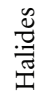<smiles>O=[N+]([O-])c1cc([N+](=O)[O-])c(F)cc1F</smiles><smiles>O=[N+]([O-])c1cc(S(=O)(=O)c2ccc(F)c([N+](=O)[O-])c2)ccc1F</smiles>

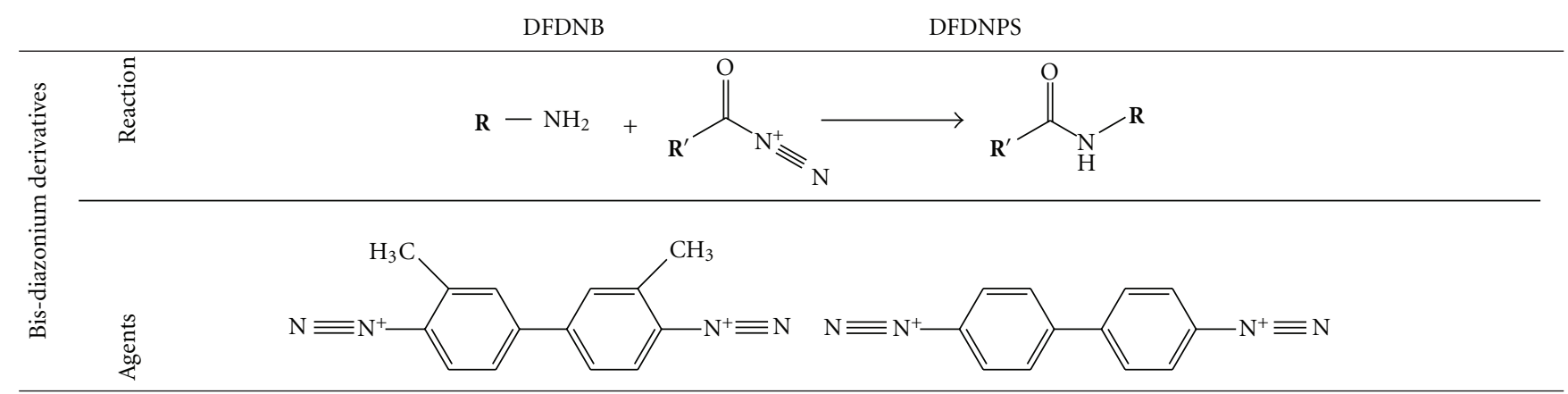


TABle 1: Continued.
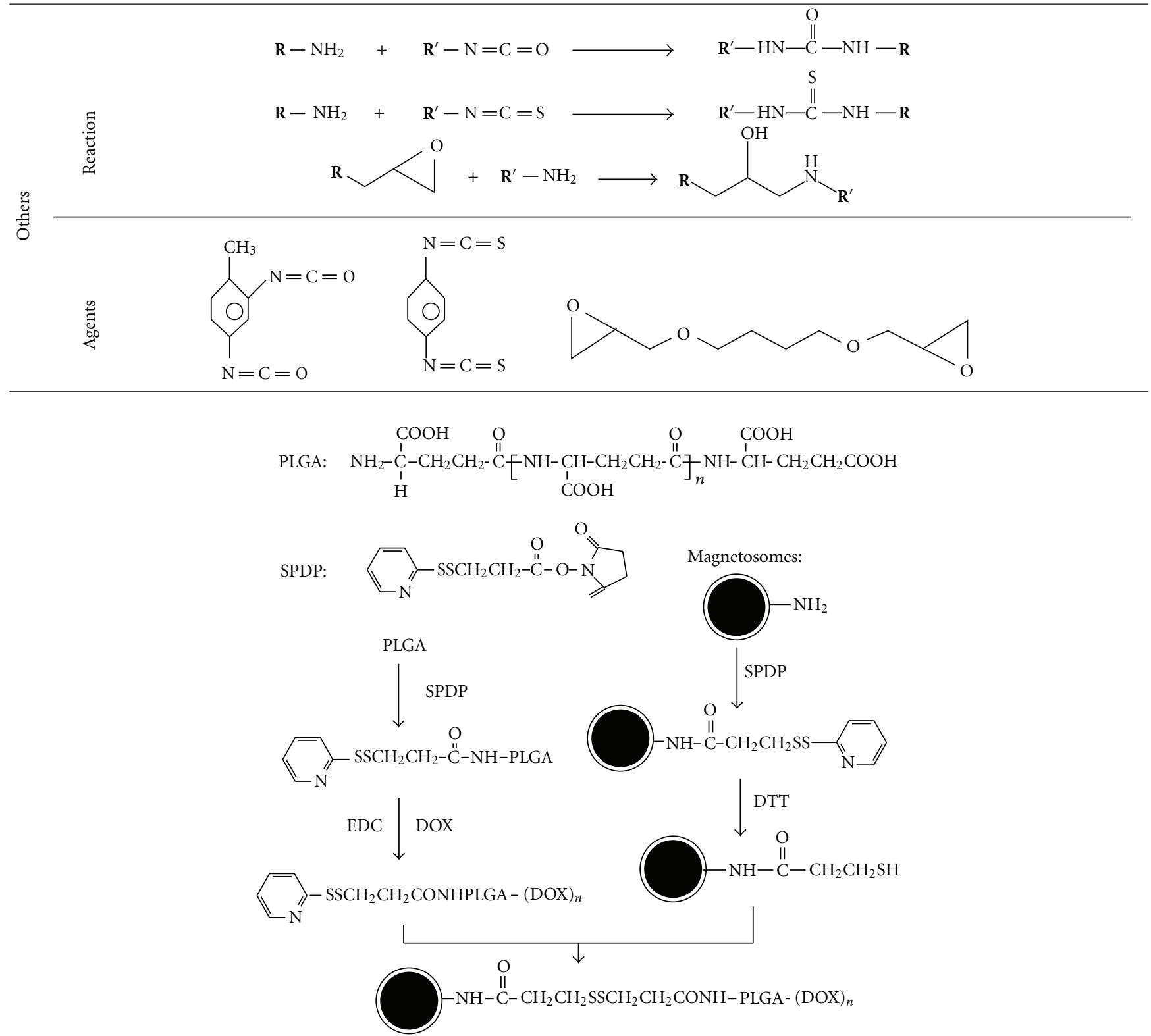

FIgURe 2: Schematic diagram of using PLGA as a bridge to link DOX with BMs.

Yoshino et al. established a method for displaying functional proteins on BMPs [63-65]. A novel promoter, termed msp3 promoter, was identified for the strong expression of $\mathrm{BMs}^{\prime}$ membrane-specific protein using $\mathrm{M}$. magneticum AMB-1 genome and proteome databases. The msp3 promoter showed 400 times higher activity than the magA promoter previously used. Efficient protein display on BMs was performed using the newly identified promoter sequences. This developed display system will facilitate the assembly of various functional proteins onto BMs.

5.2. Nucleic Acid Drugs. Nucleic acids, DNA, and RNA are endogenous materials which encode genetic information responsible for the biological process and also for dreadful diseases as well. The nucleic acids act as drugs through different mechanisms such as binding with the synthesized proteins and hybridizing to a messenger RNA, that leads to translation altering or inducing degradation of target RNA. Through this process, the nucleic acids act as drugs for gene expression and regulation. BMs were reported for DNA and RNA extraction and gene delivery and detection $[57,58,67-$ 71].

BMs have a negatively charged surface and a membrane that contains $25 \%$ phosphatidylethanolamino and can absorb much lower nucleic acids (less than 0.5 ug DNA per $100 \mathrm{ug}$ BMs) directly. Matsunaga's group modified BMs with cationic silanes such as $\mathrm{N}$ (trimethoxysilylpropyl) isothiouronium chloride, 3-Aminopropyltriethoxysi- 


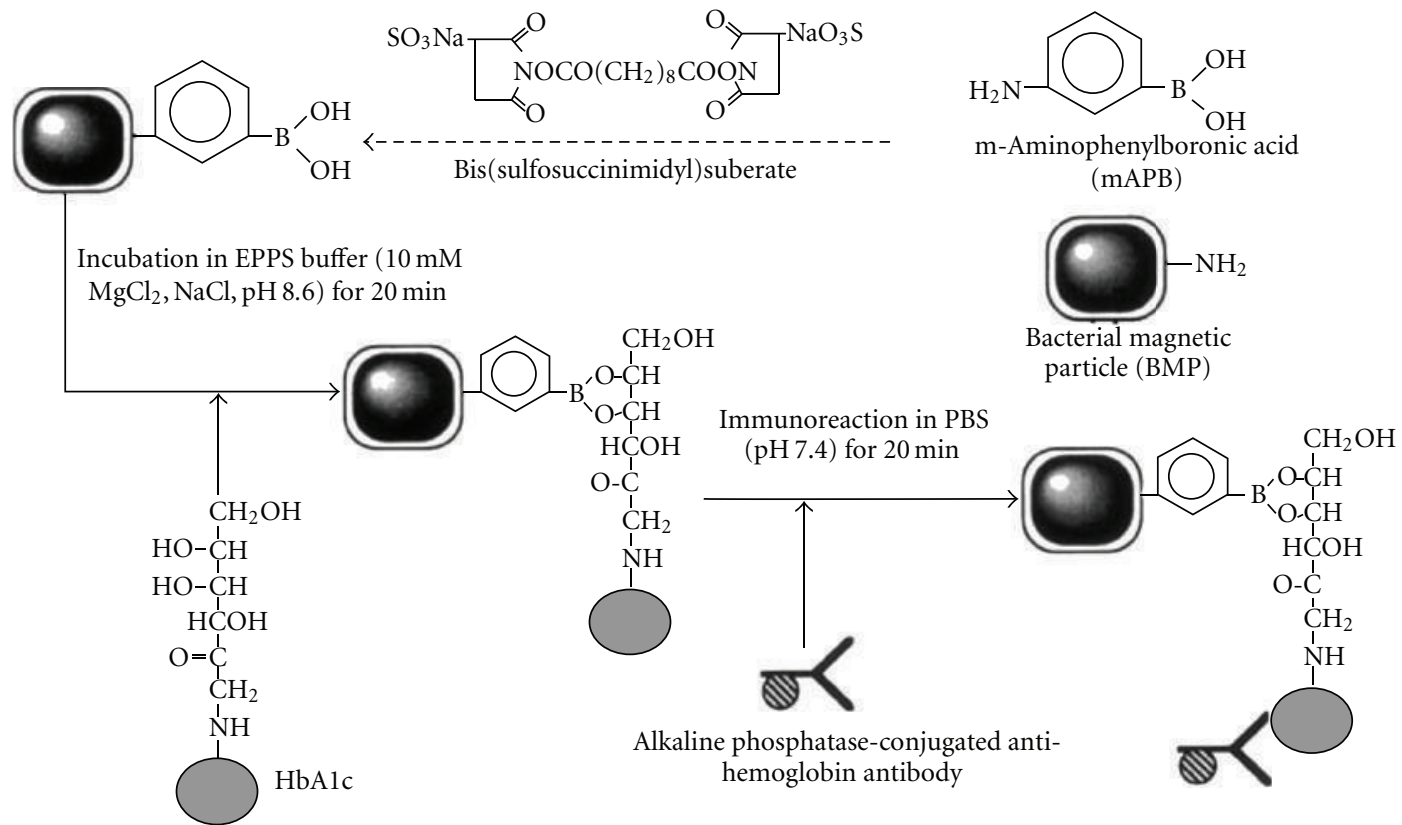

FIGURE 3: Schematic diagram of the boronate affinity immunoassay using mAPB-BMPs and alkaline phosphatase-conjugated anti-Ho antibody (ALP-antibody) [62].

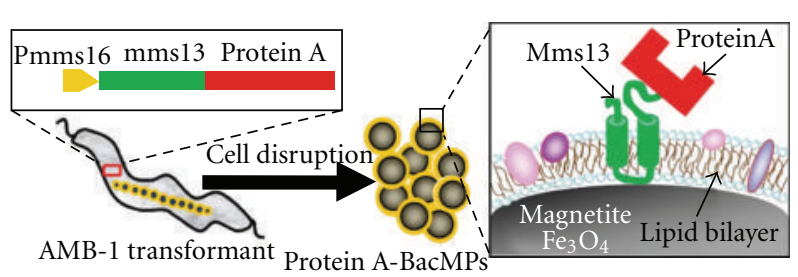

(a)

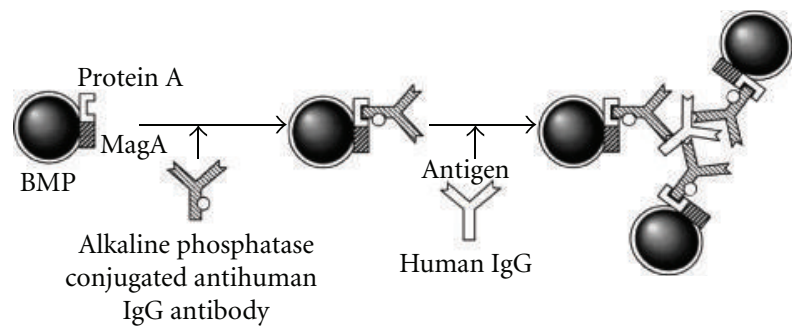

(b)

FIGURE 4: Schematic diagram of production of Protein A-BMs (A) and the homogenous chemiluminescence enzyme immunoassay using Protein A-BMs complexes [52, 65].

lane, and 3-[2-(2-aminoethyl)-ethylamino]-propyltrimethoxysilane. The DNA binding efficiency of the modified BMs increased with the number of amino groups presented on the silane compounds and was 14-fold higher than that of untreated BMs [57]. They also developed a better method of direct formation of a cascading hyperbranched polyamidoamino dendrimer onto the surface of amino silane modified BMs (Figure 5) [58]. Characterization of the synthesis revealed linear doubling of the surface amino charge from generations one through five starting with an amino silane initiator. The dendrimer modified BMs have been used to carry out magnetic separation of DNA. Binding and release efficiencies increased with the number of generations of dendrimer. The binding and release efficiencies of bacterial magnetite modified with six-generation dendrimer $(1.7 \times 106 \mathrm{aminos} / \mathrm{BM})$ were 7 and 11 times, compared with bacterial magnetites modified with only amino silane.

The Matsunaga group also immobilized biotin-labeled oligonucleotide probes onto BMs, which were modified with Sulfo-NHS-LC-LC-biotin and streptavidin [68-71]. A semiautomated system for the large-scale detection of single nucleotide polymorphisms (SNPs) has been developed with these probes-BMs particles [71]. Matsunaga et al. developed this method which binds nucleic acid fragments or protein to BMs modified with dual functional reagents after several reaction steps [71]. Biotin groups were attached to the magnetosome membrane either by incorpration of [1,2-dipalmitoyl-sn-glycero-3-phosphoethanolamino-N(biotinyl)(sodiumsalt)] (biotin-DPPE) or by the covalent modification of the proteins within the magnetosome membrane using sulfo-N-hydroxy-succinimide ester sodium salt (NHS-biotin). Magnetosomes modified with surface-bound biotin groups were used to bind streptavidin (STV), and the resulting STV-functionalized BMs were functionalized with biotinylated DNA oligomers and/or antibodies.

5.3. Radioactive Isotopes. Radiotherapy can be used to treat diseases, especially cancer, using radiation to weaken or destroy particular targeted cells. Different types of radiation sources such as X-rays, $\gamma$-rays, particle beams, protons or neutrons are used to destroy the cancer cells within 


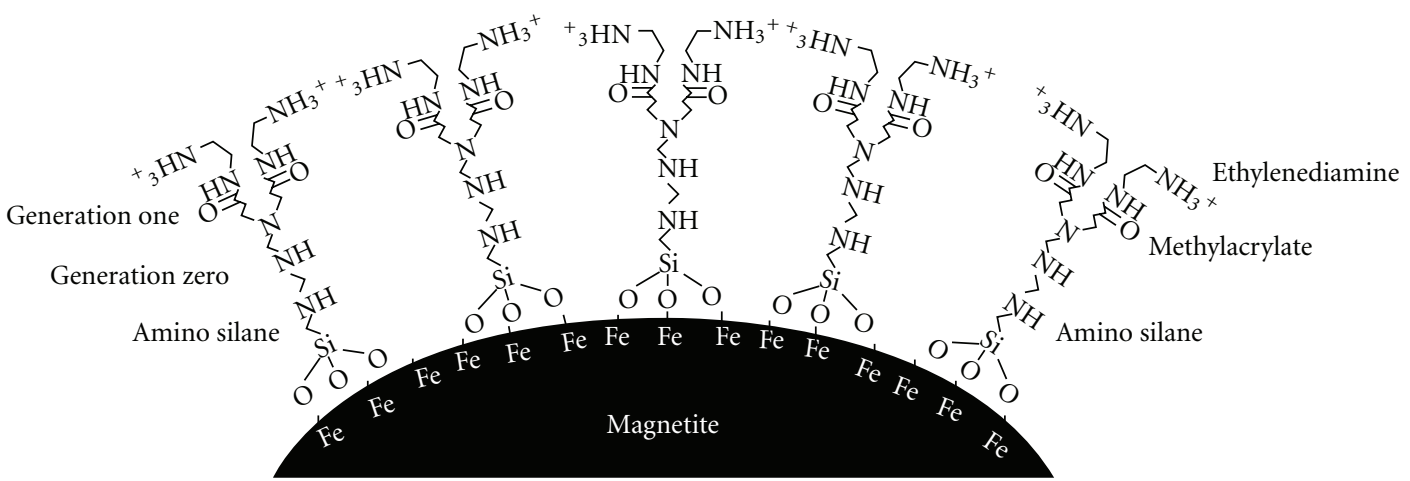

Figure 5: Structure of amino silane modified bacterial magnetite dendrimer [58].

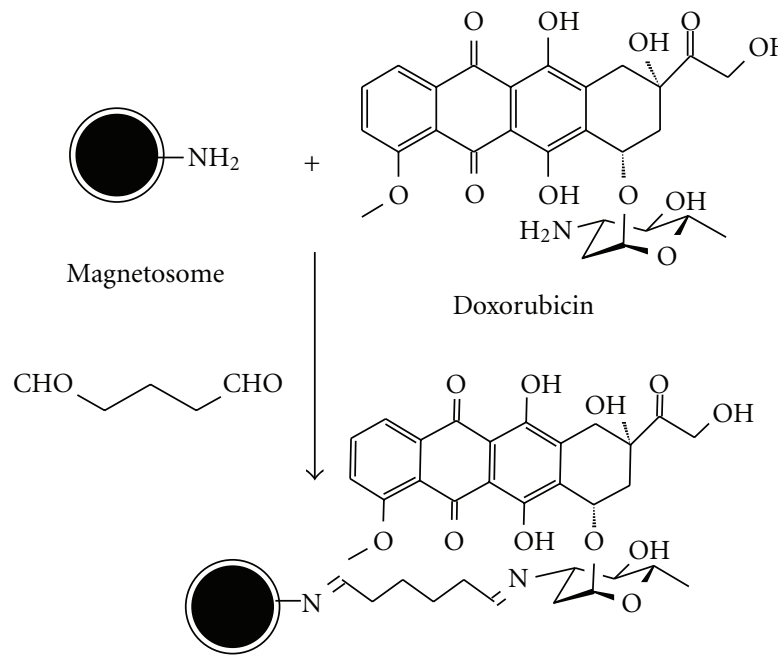

DOX-loaded magnetosome (DBM)

FIGURE 6: Schematic diagram for preparing DBMs with glutaraldehyde [66].

the body $[72,73]$. The most commonly used radioactive isotope in clinic is technetium-99, and accounts for $80 \%$ of nuclear medicine procedures. In the US alone, over 18 million nuclear medicine procedures are recorded each year. Radioactive isotopes such as $99 \mathrm{mTc}, 131 \mathrm{I}, 123 \mathrm{I}$, and $111 \mathrm{In}$ can be linked to BMs with suitable chelates, radioactivelabeled molecules such as nucleic acids and proteins, and by including the radioactive isotopes in culture medium during BMs' formation. BMs labeled with radioactive isotopes show advantages in internal radiation or brachytherapy of solid tumors due to their targeted delivery.

5.4. Chemotherapeutic Drugs. The era of cancer chemotherapy began in the 1940s with the use of nitrogen mustards and folic acid antagonist drugs, and cancer drug development has been used widely since then $[74,75]$. Modern chemotherapy avails itself, further to the cytotoxic drugs, of further agents that are differentiation inductors, radiosensitising agents, biological response modifiers, and/or agents capable of inducing hypoxia in the neoplastic clone

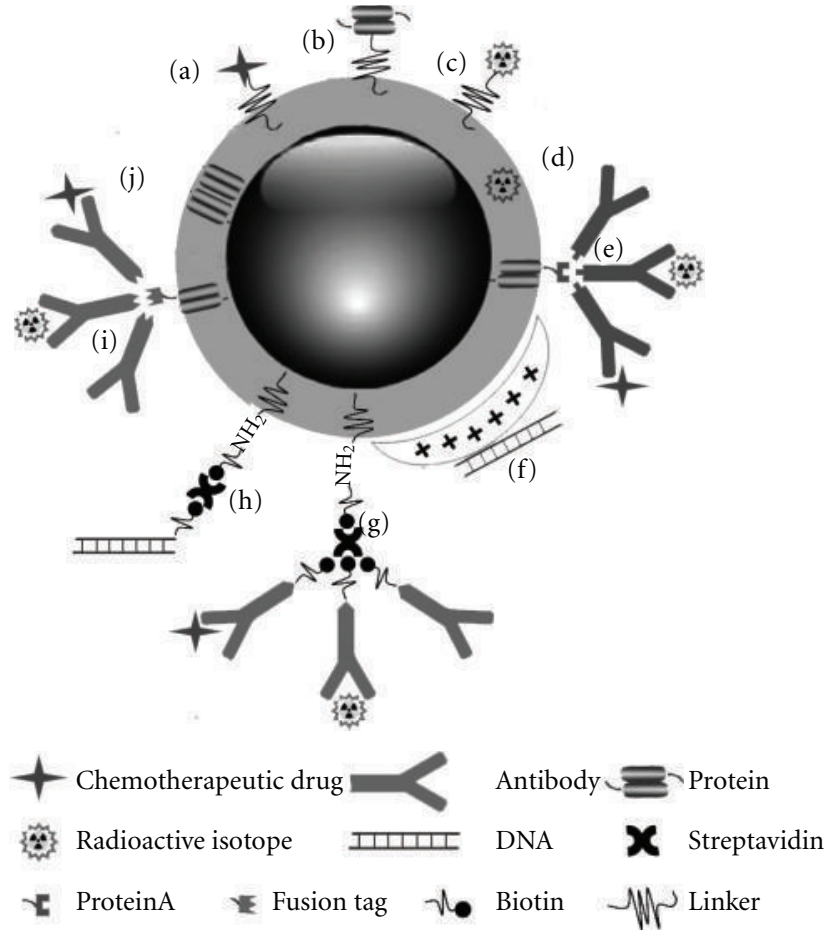

FIGURE 7: Schematic diagram of multifunctional BMs. Chemotherapeutic drug (a), protein drug (b), and radioactive isotope (c) could be loaded onto BMs by cross linkers or chelators. Radioactive isotopes could be incorporated in the membrane of BMs during the formation of BMs (d). Antibodies modified with or without radioactive isotopes or chemotherapeutic drugs could be loaded onto BMs by immunoconjugating the genetic engineering expressed Protein A (e) or fusion protein tag (i) or by streptavidinmediated conjugation with the biotin-streptavidin-biotin (g). DNA drugs could be absorbed onto BMs modified with cationic silanes (f) or linked to BMs with biotin-streptavidin-biotin (h). Specific protein drug could be expressed in BMs membrane by genetic fusion to BMs membrane protein (j).

cells. The majority of chemotherapeutic drugs can be divided into alkylating agents, antimetabolites, anthracyclines, plant alkaloids, topoisomerase inhibitors, and other antitumour agents [76]. All of these drugs affect cell division or DNA 
synthesis and function in some way. The activities of the most chemotherapeutic drugs suffer from the inability to accumulate selectively at the site of action. Drug targeting may attenuate adverse effects.

BMs' membrane contains an abundance of primary amino groups which can be modified and/or linked with chemotherapeutic drugs by various strategies mentioned above. Sun et al. provided an effective method of loading doxorubicin (DOX) onto BMs with glutaradehyde (Figure 6) and explored the clinical potential of magnetosomes as drug carriers in target therapy of cancers [13, 66]. Cancer suppressant effects in response to DOX-loaded BMs (DBMs) was evaluated. The DBMs prepared were cytotoxic to H22, HL60, and EMT-6 cells with inhibition of cell proliferation, suppression in c-myc expression, and diminishment of cell size and DNA content, which is consistent with free DOX. The in vivo antitumor effects were evaluated in $\mathrm{BABL} / \mathrm{c}$ mice bearing tumors formed with $\mathrm{H} 22$ cells. In $\mathrm{H} 22$ cell-bearing mice, DBMs, DOX, and BMs displayed tumor suppression rates of $86.8 \%, 78.6 \%$, and $4.3 \%$, respectively. The mortality rates following administration of DBMs, DOX, and BMs were $20 \%, 80 \%$, and $0 \%$, respectively. Pathological examination of hearts and tumors revealed that both DBMs and DOX effectively inhibited tumor growth, but DBMs displayed a much lower cardiac toxicity compared with DOX.

\section{Prospective}

Magnetosomes are shown to be excellent magnetic nanocarriers for antibodies, enzymes, ligands, nucleic acids, and chemotherapeutic drugs. It was reported that functionalized magnetosomes could be used for DNA/RNA recovery, ELISA, cell sorting, target therapy of cancers, gene delivery, and as a contrast agent in MRI and cellular markers for gene expression. Although most of these studies are still at the proof-of-concept stage, and each study showed only one type of potential application of magnetosomes, these findings indicated that it will be very easy to develop multifunctional magnetosomes for clinical application. For instance, magnetosomes premodified with anticancer drugs can be linked with radioactive isotope-labeled antibodies and can recognize carcinoembryonic antigens. The multifunctional magnetosomes can simultaneously be used as molecular probes for tumor detection with MRI and as targeting drug carriers for tumor chemotherapy and radioimmunotherapy combined with magnetic hyperthermia (Figure 7). There are great potentials for the preclinical and clinical applications of the BMs.

\section{Acknowledgments}

This paper was supported in part by Chinese High Technology Research and Development Program (no. 2007AA021805), Chinese Natural Science Foundation project (no. 30970784), National Key Basic Research Program of China (2009CB930200), Chinese Academy of Sciences (CAS) "Hundred Talents Program" (07165111ZX), and CAS Knowledge Innovation Program. This paper was also supported by DoD USAMRMC W81XWH-10-1-0767 and NIH/NCRR/RCMI G12 RR003048 grants.

\section{References}

[1] P. Couvreur, B. Kante, and L. Grislain, "Toxicity of polyalkylcyanoacrylate nanoparticles. II: doxorubicin-loaded nanoparticles," Journal of Pharmaceutical Sciences, vol. 71, no. 7, pp. 790-792, 1982.

[2] G. A. Hughes, "Nanostructure-mediated drug delivery," Nanomedicine, vol. 1, no. 1, pp. 22-30, 2005.

[3] M. Yokoyama, "Drug targeting with nano-sized carrier systems," Journal of Artificial Organs, vol. 8, no. 2, pp. 77-84, 2005.

[4] A. Singh, G. Garg, and P. K. Sharma, "Nanospheres: a novel approach for targeted drug delivery system," International Journal of Pharmaceutical Sciences Review and Research, vol. 5, no. 3, pp. 84-88, 2010.

[5] V. P. Torchilin, "Drug targeting," European Journal of Pharmaceutical Sciences, vol. 11, no. 2, pp. S81-S91, 2000.

[6] G. A. Silva, "Nanotechnology approaches for drug and small molecule delivery across the blood brain barrier," Surgical Neurology, vol. 67, no. 2, pp. 113-116, 2007.

[7] Q. A. Pankhurst, J. Connolly, S. K. Jones, and J. Dobson, "Applications of magnetic nanoparticles in biomedicine," Journal of Physics D, vol. 36, no. 13, pp. R167-R181, 2003.

[8] J. Dobson, "Magnetic nanoparticles for drug delivery," Drug Development Research, vol. 67, no. 1, pp. 55-60, 2006.

[9] J. Akhtar, R. Chaturvedi, J. Sharma et al., "Magnetized carrier as novel drug delivery system," International Journal of Drug Delivery Technology, vol. 1, no. 1, pp. 28-35, 2009.

[10] K. J. Widder, A. E. Senyei, and D. G. Scarpelli, "Magnetic microspheres: a model system for site specific drug delivery in vivo," Proceedings of the Society for Experimental Biology and Medicine, vol. 158, no. 2, pp. 141-146, 1978.

[11] D. L. Balkwill, D. Maratea, and R. P. Blakemore, "Ultrastructure of a magnetotactic spirillum," Journal of Bacteriology, vol. 141, no. 3, pp. 1399-1408, 1980.

[12] M. Hopkin, "Magnet-making bacteria could target tumours," Naturenews, 2004.

[13] J. B. Sun, J. H. Duan, S. L. Dai et al., "In vitro and in vivo antitumor effects of doxorubicin loaded with bacterial magnetosomes (DBMs) on H22 cells: the magnetic bionanoparticles as drug carriers," Cancer Letters, vol. 258, no. 1, pp. 109-117, 2007.

[14] V. K. Varadan, L. Chen, and J. Xie, "Magnetosomes and their biomedical applications," in Nanomedicine, pp. 175-213, John Wiley \& Sons, Chichester, UK, 2008.

[15] J. Xie, K. Chen, and X. Chen, "Production, modification and bio-applications of magnetic nanoparticles gestated by magnetotactic bacteria," Nano Research, vol. 2, no. 4, pp. 261278, 2009.

[16] D. A. Bazylinski, A. J. Garratt-Reed, and R. B. Frankel, "Electron microscopic studies of magnetosomes in magnetotactic bacteria," Microscopy Research and Technique, vol. 27, no. 5, pp. 389-401, 1994.

[17] A. Hoell, A. Wiedenmann, U. Heyen, and D. Schüler, "Nanostructure and field-induced arrangement of magnetosomes studied by SANSPOL," Physica B, vol. 350, no. 1-3, pp. E309E313, 2004.

[18] Y. A. Gorby, T. J. Beveridge, and R. P. Blakemore, "Characterization of the bacterial magnetosome membrane," Journal of Bacteriology, vol. 170, no. 2, pp. 834-841, 1988. 
[19] N. Nakamura, K. Hashimoto, and T. Matsunaga, "Immunoassay method for the determination of immunoglobulin $\mathrm{G}$ using bacterial magnetic particles," Analytical Chemistry, vol. 63, no. 3, pp. 268-272, 1991.

[20] K. Grünberg, E. C. Müller, A. Otto et al., "Biochemical and proteomic analysis of the magnetosome membrane in magnetospirillum gryphiswaldense," Applied and Environmental Microbiology, vol. 70, no. 2, pp. 1040-1050, 2004.

[21] U. Lins, F. Freitas, C. N. Keim, and M. Farina, "Electron spectroscopic imaging of magnetotactic bacteria: magnetosome morphology and diversity," Microscopy and Microanalysis, vol. 6 , no. 5, pp. 463-470, 2000.

[22] D. Schüler and R. B. Frankel, "Bacterial magnetosomes: microbiology, biomineralization and biotechnological applications," Applied Microbiology and Biotechnology, vol. 52, no. 4, pp. 464473, 1999.

[23] D. Schüler, "The biomineralization of magnetosomes in Magnetospirillum gryphiswaldense," International Microbiology, vol. 5, no. 4, pp. 209-214, 2002.

[24] J. B. Sun, Z. L. Wang, J. H. Duan et al., “Targeted distribution of bacterial magnetosomes isolated from magnetospirillum gryphiswaldense MSR-1 in healthy sprague-dawley rats," Journal of Nanoscience and Nanotechnology, vol. 9, no. 3, pp. 1881-1885, 2009.

[25] M. Pósfai, P. R. Buseck, D. A. Bazylinski, and R. B. Frankel, "Reaction sequence of iron sulfide minerals in bacteria and their use as biomarkers," Science, vol. 280, no. 5365, pp. 880 $883,1998$.

[26] M. Tanaka, Y. Okamura, A. Arakaki, T. Tanaka, H. Takeyama, and T. Matsunaga, "Origin of magnetosome membrane: proteomic analysis of magnetosome membrane and comparison with cytoplasmic membrane," Proteomics, vol. 6, no. 19, pp. 5234-5247, 2006.

[27] T. Matsunaga, M. Nemoto, A. Arakaki, and M. Tanaka, "Proteomic analysis of irregular, bullet-shaped magnetosomes in the sulphate-reducing magnetotactic bacterium Desulfovibrio magneticus RS-1," Proteomics, vol. 9, no. 12, pp. 3341-3352, 2009.

[28] T. Tanaka and T. Matsunaga, "Fully automated chemiluminescence immunoassay of insulin using antibody-Protein Abacterial magnetic particle complexes," Analytical Chemistry, vol. 72, no. 15, pp. 3518-3522, 2000.

[29] A. Vonarbourg, C. Passirani, P. Saulnier, and J. P. Benoit, "Parameters influencing the stealthiness of colloidal drug delivery systems," Biomaterials, vol. 27, no. 24, pp. 4356-4373, 2006.

[30] L. Juillerat-Jeanneret and F. Schmitt, "Chemical modification of therapeutic drugs or drug vector systems to achieve targeted therapy: looking for the grail," Medicinal Research Reviews, vol. 27, no. 4, pp. 574-590, 2007.

[31] B. M. Moskowitz, R. B. Frankel, P. J. Flanders, R. P. Blakemore, and B. B. Schwartz, "Magnetic properties of magnetotactic bacteria," Journal of Magnetism and Magnetic Materials, vol. 73, no. 3, pp. 273-288, 1988.

[32] R. E. Dunin-Borkowski, M. R. McCartney, R. B. Frankel, D. A. Bazylinski, M. Pósfai, and P. R. Buseck, "Magnetic microstructure of magnetotactic bacteria by electron holography," Science, vol. 282, no. 5395, pp. 1868-1870, 1998.

[33] M. Timko, A. Džarová, P. Kopčanský et al., "Magnetic properties of magnetite formed by biomineralization and chemical synthesis," Acta Physica Polonica A, vol. 113, no. 1, pp. 573-576, 2008.

[34] R. Hergt, R. Hiergeist, M. Zeisberger et al., "Magnetic properties of bacterial magnetosomes as potential diagnostic and therapeutic tools," Journal of Magnetism and Magnetic Materials, vol. 293, no. 1, pp. 80-86, 2005.

[35] O. Felfoul, M. Mohammadi, and S. Martel, "Magnetic resonance imaging of $\mathrm{Fe} 3 \mathrm{O} 4$ nanoparticles embedded in living magnetotactic bacteria for potential use as carriers for in Vivo applications," in Proceedings of the 29th Annual International Conference of IEEE-EMBS, Engineering in Medicine and Biology Society (EMBC'07), pp. 1463-1466, August 2007.

[36] F. C. Meldrum, S. Mann, B. R. Heywood, R. B. Frankel, and D. A. Bazylinski, "Electron microscopy study of magnetosomes in two cultured vibrioid magnetotactic bacteria," Proceedings of the Royal Society B, vol. 251, no. 1332, pp. 237-242, 1993.

[37] A. R. Muxworthy and W. Williams, "Critical superparamagnetic/single-domain grain sizes in interacting magnetite particles: implications for magnetosome crystals," Journal of the Royal Society Interface, vol. 6, no. 41, pp. 1207-1212, 2009.

[38] I. Penninga, H. de Waard, B. M. Moskowitz, D. A. Bazylinski, and R. B. Frankel, "Remanence measurements on individual magnetotactic bacteria using a pulsed magnetic field," Journal of Magnetism and Magnetic Materials, vol. 149, no. 3, pp. 279286, 1995.

[39] C. U. Herborn, N. Papanikolaou, R. Reszka, K. Grünberg, D. Schüler, and J. F. Debatin, "Magnetosomes as biological model for iron binding: relaxivity determination with MRI," Fortschr Röntgenstr, vol. 175, no. 6, pp. 830-834, 2003.

[40] D. Eberbeck, V. Janke, S. Hartwig et al., "Blocking of magnetic moments of magnetosomes measured by magnetorelaxometry and direct observation by magnetic force microscopy," Journal of Magnetism and Magnetic Materials, vol. 289, pp. 70-73, 2005.

[41] R. Hergt, S. Dutz, R. Müller, and M. Zeisberger, "Magnetic particle hyperthermia: nanoparticle magnetism and materials development for cancer therapy," Journal of Physics Condensed Matter, vol. 18, no. 38, article S26, pp. S2919-S2934, 2006.

[42] E. Alphandéry, S. Faure, L. Raison, E. Duguet, P. A. Howse, and D. A. Bazylinski, "Heat production by bacterial magnetosomes exposed to an oscillating magnetic field," The Journal of Physical Chemistry C, vol. 115, no. 1, pp. 18-22, 2011.

[43] L. L. Hu, F. Zhang, Z. Wang et al., "Comparison of the $1 \mathrm{H}$ NMR relaxation enhancement produced by bacterial magnetosomes and synthetic iron oxide nanoparticles for potential use as MR molecular probes," IEEE Transactions on Applied Superconductivity, vol. 20, no. 3, pp. 822-825, 2010.

[44] U. O. Häfeli and G. J. Pauer, "In vitro and in vivo toxicity of magnetic microspheres," Journal of Magnetism and Magnetic Materials, vol. 194, no. 1, pp. 76-82, 1999.

[45] V. Wagner, A. Dullaart, A. K. Bock, and A. Zweck, "The emerging nanomedicine landscape," Nature Biotechnology, vol. 24, no. 10, pp. 1211-1217, 2006.

[46] L. Xiang, J. Wei, S. Jianbo, W. Guili, G. Feng, and L. Ying, "Purified and sterilized magnetosomes from Magnetospirillum gryphiswaldense MSR-1 were not toxic to mouse fibroblasts in vitro," Letters in Applied Microbiology, vol. 45, no. 1, pp. 75-81, 2007.

[47] J. Sun, T. Tang, J. Duan et al., "Biocompatibility of bacterial magnetosomes: acute toxicity, immunotoxicity and cytotoxicity," Nanotoxicology, vol. 4, no. 3, pp. 271-283, 2010.

[48] J. A. Kim, H. J. Lee, H. J. Kang, and T. H. Park, “The targeting of endothelial progenitor cells to a specific location within a microfluidic channel using magnetic nanoparticles," Biomedical Microdevices, vol. 11, no. 1, pp. 287-296, 2009.

[49] A. Fischer, M. Schmitz, B. Aichmayer, P. Fratzl, and D. Faivre, "Structural purity of magnetite nanoparticles in magnetotactic 
bacteria," Journal of the Royal Society Interface, vol. 8, no. 60, pp. 1011-1018, 2011.

[50] J. B. Sun, F. Zhao, T. Tang et al., "High-yield growth and magnetosome formation by Magnetospirillum gryphiswaldense MSR-1 in an oxygen-controlled fermentor supplied solely with air," Applied Microbiology and Biotechnology, vol. 79, no. 3, pp. 389-397, 2008.

[51] Y. Liu, G. R. Li, F. F. Guo, W. Jiang, Y. Li, and L. J. Li, "Largescale production of magnetosomes by chemostat culture of Magnetospirillum gryphiswaldense at high cell density," Microbial Cell Factories, vol. 9, article 99, 2010.

[52] T. Matsunaga, R. Sato, S. Kamiya, T. Tanaka, and H. Takeyama, "Chemiluminescence enzyme immunoassay using ProteinAbacterial magnetite complex," Journal of Magnetism and Magnetic Materials, vol. 194, no. 1, pp. 126-131, 1999.

[53] G. Hermanson, Bioconjugate Techniques, Academic Press, New York, NY, USA, 2nd edition, 2008.

[54] N. Nakamura, J. G. Burgess, K. Yagiuda, S. Kudo, T. Sakaguchi, and T. Matsunaga, "Detection and removal of Escherichia coli using fluorescein isothiocyanate conjugated monoclonal antibody immobilized on bacterial magnetic particles," Analytical Chemistry, vol. 65, no. 15, pp. 2036-2039, 1993.

[55] N. Nakamura and T. Matsunaga, "Highly sensitive detection of allergen using bacterial magnetic particles," Analytica Chimica Acta, vol. 281, no. 3, pp. 585-589, 1993.

[56] Y. Kato, N. Umemoto, Y. Kayama et al., "A novel method of conjugation of daunomycin with antibody with a polyL-glutamic acid derivative as intermediate drug carrier. An anti- $\alpha$-fetoprotein antibody-daunomycin conjugate," Journal of Medicinal Chemistry, vol. 27, no. 12, pp. 1602-1607, 1984.

[57] B. Yoza, M. Matsumoto, and T. Matsunaga, "DNA extraction using modified bacterial magnetic particles in the presence of amino silane compound," Journal of Biotechnology, vol. 94, no. 3, pp. 217-224, 2002.

[58] B. Yoza, A. Arakaki, and T. Matsunaga, "DNA extraction using bacterial magnetic particles modified with hyperbranched polyamidoamine dendrimer," Journal of Biotechnology, vol. 101, no. 3, pp. 219-228, 2003.

[59] T. Matsunaga, A. Arakaki, and M. Takahoko, "Preparation of luciferase-bacterial magnetic particle complex by artificial integration of MagA-luciferase fusion protein into the bacterial magnetic particle membrane," Biotechnology and Bioengineering, vol. 77, no. 6, pp. 614-618, 2002.

[60] I. M. Tomlinson, "Next-generation protein drugs," Nature Biotechnology, vol. 22, no. 5, pp. 521-522, 2004.

[61] T. Matsunaga and S. Kamiya, "Use of magnetic particles isolated from magnetotactic bacteria for enzyme immobilization," Applied Microbiology and Biotechnology, vol. 26, no. 4, pp. 328-332, 1987.

[62] T. Tanaka and T. Matsunaga, "Detection of HbAlc by boronate affinity immunoassay using bacterial magnetic particles," Biosensors and Bioelectronics, vol. 16, no. 9-12, pp. 1089-1094, 2001.

[63] T. Yoshino and T. Matsunaga, "Development of efficient expression system for protein display on bacterial magnetic particles," Biochemical and Biophysical Research Communications, vol. 338, no. 4, pp. 1678-1681, 2005.

[64] T. Yoshino, F. Kato, H. Takeyama, M. Nakai, Y. Yakabe, and T. Matsunaga, "Development of a novel method for screening of estrogenic compounds using nano-sized bacterial magnetic particles displaying estrogen receptor," Analytica Chimica Acta, vol. 532, no. 2, pp. 105-111, 2005.

[65] T. Yoshino, H. Hirabe, M. Takahashi, M. Kuhara, H. Takeyama, and T. Matsunaga, "Magnetic cell separation using nano-sized bacterial magnetic particles with reconstructed magnetosome membrane," Biotechnology and Bioengineering, vol. 101, no. 3, pp. 470-477, 2008.

[66] J. B. Sun, J. H. Duan, S. L. Dai et al., "Preparation and antitumor efficiency evaluation of doxorubicin-loaded bacterial magnetosomes: magnetic nanoparticles as drug carriers isolated from Magnetospirillum gryphiswaldense," Biotechnology and Bioengineering, vol. 101, no. 6, pp. 1313-1320, 2008.

[67] H. Takeyama, A. Yamazawa, C. Nakamura, and T. Matsunaga, "Application of bacterial magnetic particles as novel DNA carriers for ballistic transformation of a marine cyanobacterium," Biotechnology Techniques, vol. 9, no. 5, pp. 355-360, 1995.

[68] H. Ota, H. Takeyama, H. Nakayama, T. Katoh, and T. Matsunaga, "SNP detection in transforming growth factor$\beta 1$ gene using bacterial magnetic particles," Biosensors and Bioelectronics, vol. 18, no. 5-6, pp. 683-687, 2003.

[69] K. Maruyama, H. Takeyame, E. Nemoto, T. Tanaka, K. Yoda, and T. Matsunaga, "Single nucleotide polymorphism detection in aldehyde dehydrogenase 2 (ALDH2) gene using bacterial magnetic particles based on dissociation curve analysis," Biotechnology and Bioengineering, vol. 87, no. 6, pp. 687-694, 2004.

[70] B. Ceyhan, P. Alhorn, C. Lang, D. Schüler, and C. M. Niemeyer, "Semisynthetic biogenic magnetosome nanoparticles for the detection of proteins and nucleic acids," Small, vol. 2, no. 11, pp. 1251-1255, 2006.

[71] T. Matsunaga, K. Maruyama, H. Takeyama, and T. Katoh, "High-throughput SNP detection using nano-scale engineered biomagnetite," Biosensors and Bioelectronics, vol. 22, no. 9-10, pp. 2315-2321, 2007.

[72] C. A. Boswell and M. W. Brechbiel, "Development of radioimmunotherapeutic and diagnostic antibodies: an inside-out view," Nuclear Medicine and Biology, vol. 34, no. 7, pp. 757778, 2007.

[73] A. V. S. Anil Kumar, P. G. Kumar, and S. Shankar, "Role of nuclear medicine in evaluation and management of joint diseases," Indian Journal of Rheumatology, vol. 4, no. 2, pp. 6168, 2009.

[74] J. Hirsch, "An anniversary for cancer chemotherapy," Journal of the American Medical Association, vol. 296, no. 12, pp. 15181520, 2006.

[75] M. J. Camp, J. W. Gilmore, M. M. Gullatte et al., "Antineoplastic agents," in Clinical Guide to Antineoplastic Therapy: A Chemotherapy Handbook, M. M. Gullatte, Ed., pp. 81-356, Oncology Nursing Society, Pittsburgh, Pa, USA, 2nd edition, 2007.

[76] B. R. Minev, Cancer Management in Man: Chemotherapy, Biological Therapy, Hyperthermia and Supporting Measures, vol. 13, Springer, Dordrecht, The Netherlands, 1st edition, 2011. 

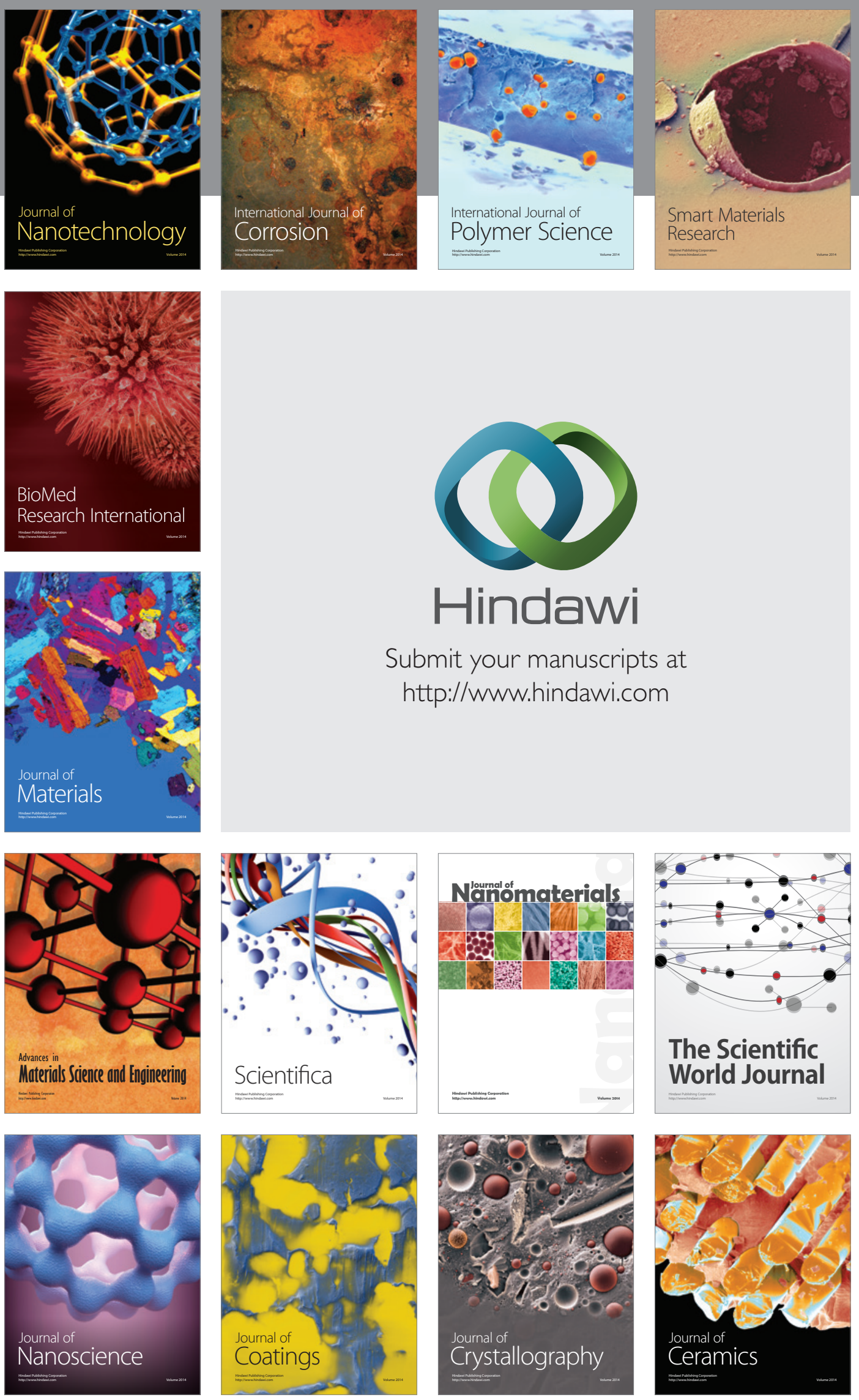

The Scientific World Journal

Submit your manuscripts at

http://www.hindawi.com

\section{World Journal}

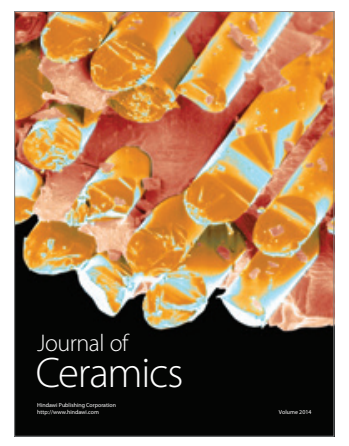

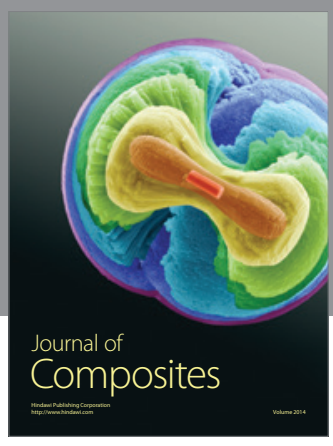
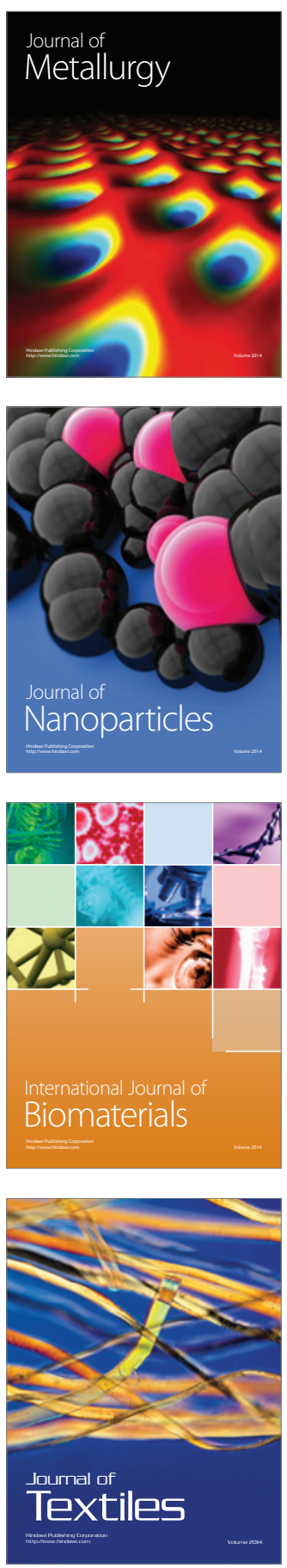